\title{
Simplified FEM modelling for the collapse assessment of a masonry vault
}

\author{
Pierluigi Olmati \\ Sapienza University of Rome, Italy (now at TAISEI Corp., Tokyo, Japan) \\ pierluigi.olmati@gmail.com
}

\section{Konstantinos Gkoumas}

Sapienza University of Rome, Italy (now at European Commission, Joint Research Centre)

konstantinos.gkoumas@uniroma1.it, bttps:/ /orcid.org/0000-0003-3833-6223

\section{Franco Bontempi}

Sapienza University of Rome, Italy

franco.bontempi@uniroma1.it, https://orcid.org/0000-0001-6377-7501

\begin{abstract}
This study is motivated from the collapse of an old masonry building in the Southern Italy. FEM analyses are carried out focusing on the influence of the contrasting wall on the stability of the vault. In the analyses, the structure is subjected to a damage scenario on the contrasting wall due to a demolition project, and the consequence of the damage is evaluated using the explicit dynamic simulation made by Ls-Dyna ${ }^{\circledR}$. A micro modelling technique (discrete FEM model) is adopted to model the masonry: the mortar is modelled by contact surfaces between the masonry units, which are explicitly modelled by blocks of meshes. This modelling technique is proven to be effective to predict the collapse behavior of the structure.
\end{abstract}

KEYWORDS. FEM; Masonry structures; Forensic investigations; Vault structures.

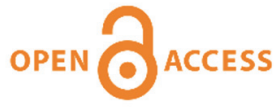

Citation: Olmati, P., Gkoumas, K., Bontempi, F., Simplified FEM modelling for the collapse assessment of a masonry vault, Frattura ed Integrità Strutturale, 47 (2019) 141-149.

Received: 21.08 .2018

Accepted: 17.11.2018

Published: 01.01.2019

Copyright: (C) 2019 This is an open access article under the terms of the CC-BY 4.0, which permits unrestricted use, distribution, and reproduction in any medium, provided the original author and source are credited.

\section{INTRODUCTION}

asonry structures are widespread in the world, built with different materials and different construction techniques. Some of them are old: masonry construction initiated in the ancient times, as early as $4.000 \mathrm{BC}$ with stonemasonry in Ancient Egypt, and culminated in the Roman era with the development of the Roman Arch. The behavior of masonry buildings is affected by the used materials, the quality of the mortar and workmanship, the assembly, and their age. 
Although superseded by concrete construction in the 20th century, there are numerous masonry residential buildings still used for housing and other scopes.

In southern Italy in particular, unreinforced masonry buildings built in the first half of the 20th century represent a significant portion of the residential building stock, especially in rural areas, with clay brick masonry being the most common material. Due to the lack of code compliance (many masonry houses were built without permit), these buildings are often dangerous, and prone to poor performance.

A lot of research has been carried out on the FEM (Finite Element Modelling) of masonry structures, considering the complexity arising from the fact that masonry is an anisotropic composite material [1-6]. Tzamtzis and Asteris [7] summarize several methods and finite element models developed for the static and dynamic analysis of unreinforced masonry walls, focusing on the constitutive model for bricks and mortar. They conclude that most of these models treat masonry, either as an ideal homogeneous material with constitutive equations that differ from those of the components, or two-phase material models where the components are considered separately to account for the interaction between them. These approaches are reported frequently as "macro modelling" or "micro modelling" [8]. More recently, Giresini et al. [9] propose a quick and simplified method to describe masonry vaults in global seismic analyses of buildings.

Fig. 1 summarizes three different modelling techniques for masonry modelling, respectively, micro- , macro- and simplified micro modelling. In the case a micro modelling approach is taken, the challenge is to describe the complex behavior of the interface between bricks and mortar. Detailed micro modelling considers bricks and mortar as separate continuous elements, while the interface between them is discontinuous. A simplification of the above is found in simplified micro-modelling, where expanded units are represented by continuous elements and mortar joints and the interface by discontinuous elements. With this model, mortar joints are ignored and replaced by interface elements, whose characteristics are based on interface behavior (see also [10]).

\begin{tabular}{|c|c|c|}
\hline $\begin{array}{l}\quad \text { Micro modeling } \\
\text { Explicit modelling of units } \\
\text { (bricks), mortar and } \\
\text { interface }\end{array}$ & $\begin{array}{l}\quad \text { Macro modeling } \\
\text { Modeled as homogeneous } \\
\text { material of intermediate } \\
\text { characteristics }\end{array}$ & $\begin{array}{l}\text { Simplified micro modeling } \\
\text { Explicit modelling of units } \\
\text { (bricks) and joints }\end{array}$ \\
\hline
\end{tabular}

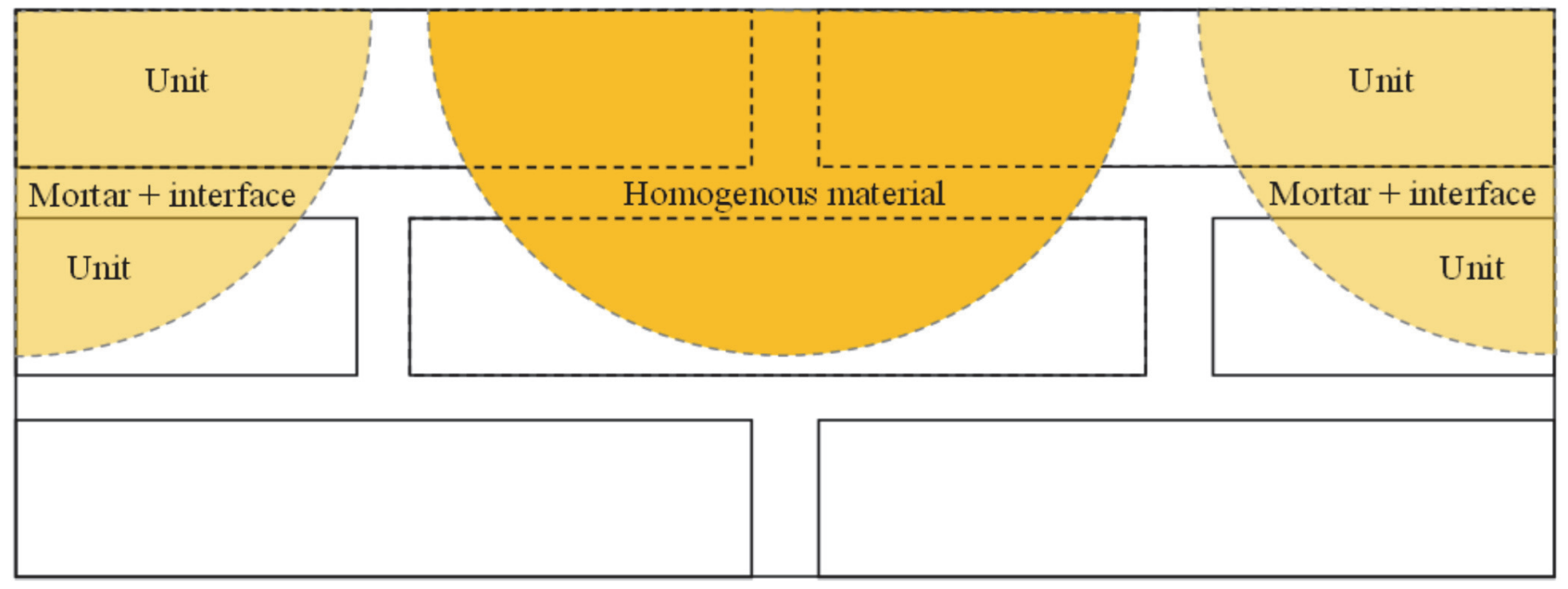

Figure 1: Modelling techniques for masonry structures

The modelling is not trivial. An important aspect for the accurate modeling is the mechanical characterization of historical masonry structures. Rovero et al. [11] perform an in situ experimental validation of the qualitative methodology developed in [12]. More recently, Maione et al. [13] focus on the management of the data derived from different sources (e.g. infrared thermography, visual inspections, architectural survey, historic analysis), providing a methodology for the complete characterization of a historic masonry building.

Furthermore, performed numerical analyses have shown that the bonding strength of the connections significantly influences the load-bearing capacity and the behavior of the structure under loading [14]. To this end, the use of simplified modelling techniques is common in the last years [15]. The reader is referred to [16] for additional modelling aspects regarding historical vault structures. 


\section{BOUNDARY CONDITIONS IN MASONRY BUILDING BLOCKS}

$\mathrm{W}$

hen dealing with existing masonry buildings there are some general aspects that should be carefully examined. Among other prescriptions, it is important to check the physical condition of masonry elements and the presence of any degradation or modification with respect to the original situation, both as an isolated structure and included in a building block. Considering the latter, the interaction with adjacent buildings potentially interacting with the building under study, should also be taken into account, for what regards the configuration of the masonry elements and their connections.

From these recommendations, it is clear that, in case of retrofitting interventions on existing adjacent buildings, a preliminary evaluation of the interactions between the buildings and an accurate and reliable investigation are necessary. Thus, the effects of the interventions on one of the buildings should be studied also to the adjacent ones, considering the different phases (demolition, excavation, rebuilding, etc.).

A group of adjacent buildings is delimited by an open space and it is composed by various adjacent non-uniform constructions. The constituting buildings are often built in different periods, with different materials. They have different owners and usually experience different uses and modifications during time. In the analysis of a single structural unit, it is necessary to take into account the possible interactions arising from the structural contiguity with the adjacent buildings. Neglecting these aspects can have significant consequences on the structures, leading even up to the occurrence of catastrophic collapses. In case of intervention on an existing building, the design approach depends on the completeness and reliability of the gathered information. Nevertheless, uncertainties need to be accounted for [17]. For this reason, the capacity parameters can be reduced by using specific confident factors that vary according to the level of knowledge. In the Eurocode 8 - Part 3 [18], for example, at a good knowledge on the structure (Knowledge level KL 3) corresponds a confident factor $(\mathrm{CF})$ equal to 1, while in case of intermediate and low knowledge (KL 2 and KL 1) the recommended values for the confident factors are respectively 1.2 and 1.35 .

\section{DESCRIPTION OF THE BUILDING COMPLEX}

$\mathrm{O}$ bject of this study is to provide a methodology for assessing the residual strength of a vault structure when the horizontal support ceases to exist. To this aim, the analysis focuses on an actual case of a collapsed portion of a building complex that followed the demolition of the other part that worked as a support for a vault. The structure, entirely built in masonry, has some significant characteristics. As in many cases for masonry structures, a criticality lies on the absence of strain resistance and on the stress resistance due to the shape. Furthermore, different parts of the building were built in different periods, complying with different standards (or not complying with standards at all). Many of the walls, including those supporting the vaults, have cores filled with rough rubble masonry.

The considered case study regards a group of adjacent constructions located in a city of the South of Italy. In Fig. 2 an aerial view of the group of buildings is shown (from [19]). In the moment the picture was taken, it was possible to clearly recognize four main units. Such units were built in different instants, starting from 1870, and then they were modified and unified. This study focuses on the buildings indicated with " $\mathrm{A}$ " (demolished) and "B" (collapsed) in Fig. 2. More precisely, the demolition of building $\mathrm{A}$ was planned and carried out without taking into account its interactions with building $\mathrm{B}$, and neglecting the consequences on its stability.

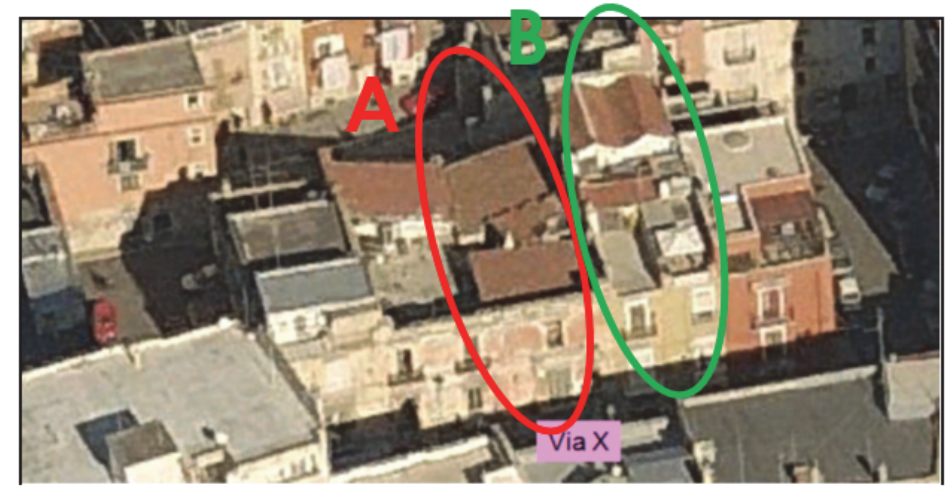

Figure 2: Aerial view of the considered group of adjacent buildings (from [17]). 
The two buildings had a common wall that supported the actions of various vaulted ceilings. Fig. 3 provides the layout of the structure under investigation, including the geometric dimensions of the bi-dimensional model, together with an overview of the modelled elements. On the left side, the pertinent volume is shown, while the wall on the far right side is considered as fixed.

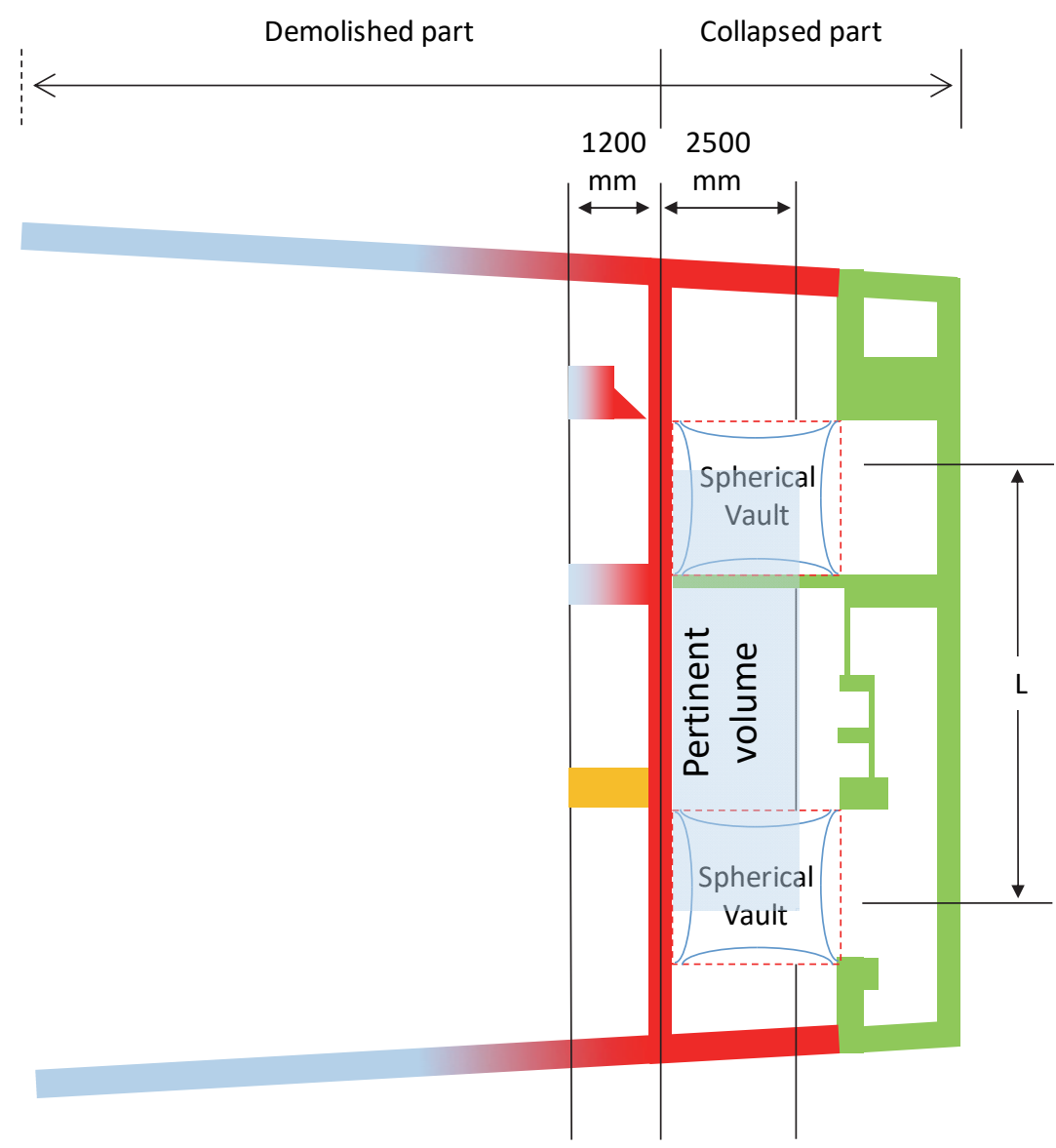

Figure 3: Layout of the building complex with the considered modeling elements

On the left side is identified the demolished part, and on the right the collapsed part, which was a consequence of the demolition. On the left side, only the relevant structural parts are reported. The right side includes two vault structures. The two parts are separated by a shared wall, which is considered as an important part for the investigation. In fact, the demolition works initiated from the left side, and the collapse of the right portion of the building complex took place when the demolished was finishing. It is normal to presume at this point that the demolished part served as a horizontal support, providing stress resistance to the vaults that collapsed on the right portion of the building.

\section{SIMPLIFIED NUMERICAL MODELLING OF THE VAULT}

I

n order to model the conditions prior and after the collapse, a FEM model is implemented (similar to [14]) in the LSDYNA numerical code (for modelling issues see [20]). Part of these results obtained by the authors are reported also in [21] and are described in later paper by Palmisano and Perilli [22].

\section{Modelling details}

Some simplifications are made. In particular, only the bi-dimensional vault structure is considered in the numerical simulation of the arch effect of the vault, and focus is given on only one of the vaults. With reference to the plan of the 
building complex before the last demolishing (Fig. 3), the hypothesis made is that the critical element is the contrasting wall (B), which contrasts the horizontal force of the vault and maybe also of the adjacent vaults/arches.

Three hypotheses are made regarding the volume of the influencing part that act (as a rectangular volume) on the contrasting wall. These hypotheses are validated by means of numerical simulations, implementing a parametric analysis. The two dimensions of the volume are fixed, and one is variable. The parallelogram volume has a height of 2.8 meters and a depth of 1.2 meters, while the third dimension (length) is considered as a variable parameter. Thus, by varying the length L, the pertinent (tributary) volume changes. Tab. 1 reports the adopted values.

\begin{tabular}{llll}
\hline Scenario & $\mathrm{S} 1$ & $\mathrm{~S} 2$ & $\mathrm{~S} 3$ \\
Length & $\mathrm{L} 1=10 \mathrm{~m}$ & $\mathrm{~L} 2=7.1 \mathrm{~m}$ & $\mathrm{~L} 3=5 \mathrm{~m}$ \\
Volume & $33.6 \mathrm{~m}^{3}$ & $23.85 \mathrm{~m}^{3}$ & $16.8 \mathrm{~m}^{3}$ \\
\hline
\end{tabular}

Table 1: Considered scenarios and corresponding tributary volume lengths.

In the considered simplified modelling approach, the blocks are individually modelled, but the mortar is modelled as a contact between the blocks (thus, the mortar is not explicitly modelled). Every single brick is meshed and the contact between bricks is modelled with non-linear properties. The coefficient of static friction is taken equal to 0.2 , while the coefficient of dynamic friction is taken equal to 0.4. The brick density is taken equal to $\mathrm{em}=1.65 \mathrm{E}-9$ ton $/ \mathrm{mm}^{3}$, while the density of the rough rubble masonry inside the core is assumed equal to $\mathrm{f}=1.4 \mathrm{E}-9 \mathrm{ton} / \mathrm{mm}^{3}$. The rubble masonry consists in poor quality unsquared stones with not good consistency. Fig. 4 shows the geometry of the FEM model (dimensions are in $\mathrm{mm})$.

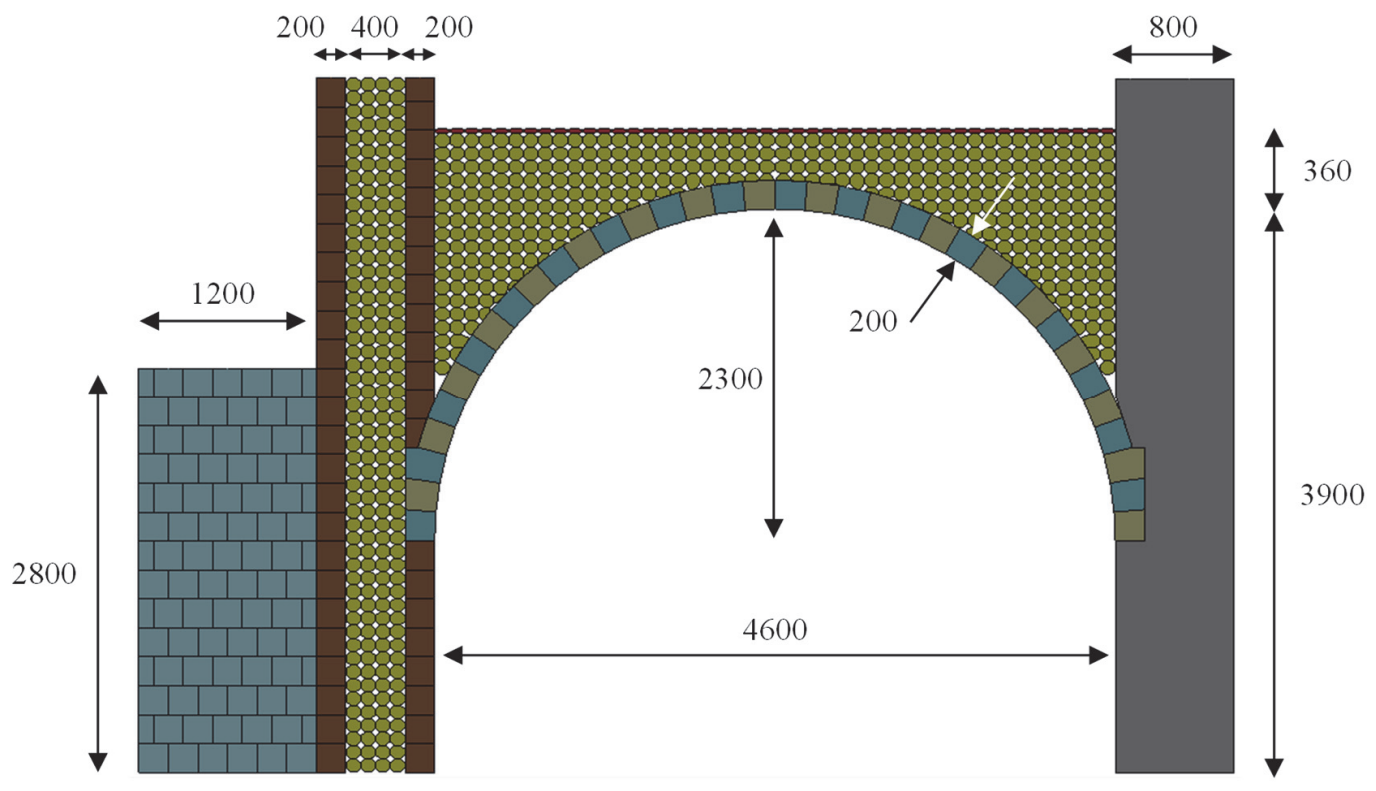

Figure 4: Geometry of the FEM model

In the model, the material properties are elastic. Each masonry element is modeled as a single object that interacts with the adjacent element through contact and friction forces. Each masonry or filling element is a discrete element. Finally, a ramp function in the time domain is used for the loading.

\section{Numerical results}

The numerical results are obtained for the three different scenarios, corresponding to the three different pertinent volumes reported in Tab. 1.

Figs. 5-7 provide the deformed shape of the structure, $0.9 \mathrm{sec}$ after the elimination of the contrasting block. It is important to state that the collapse takes place independently of the area of influence. However, the collapse rapidity changes radically depending on the considered scenario. 


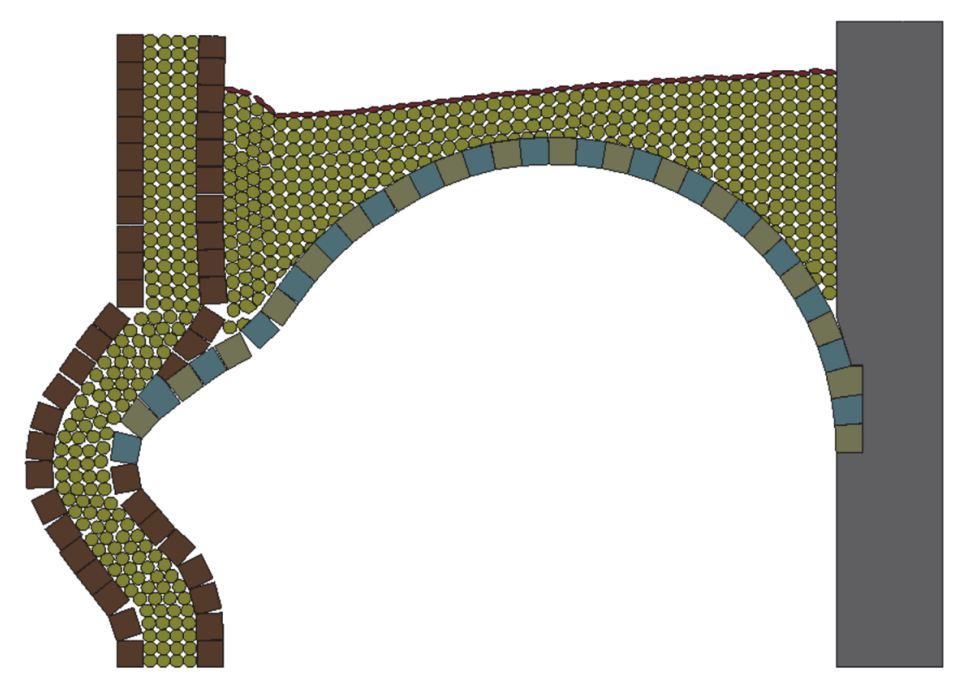

Figure 5: Deformed configuration after $0.9 \mathrm{sec}$ for scenario S1 $(\mathrm{L}=10 \mathrm{~m})$.

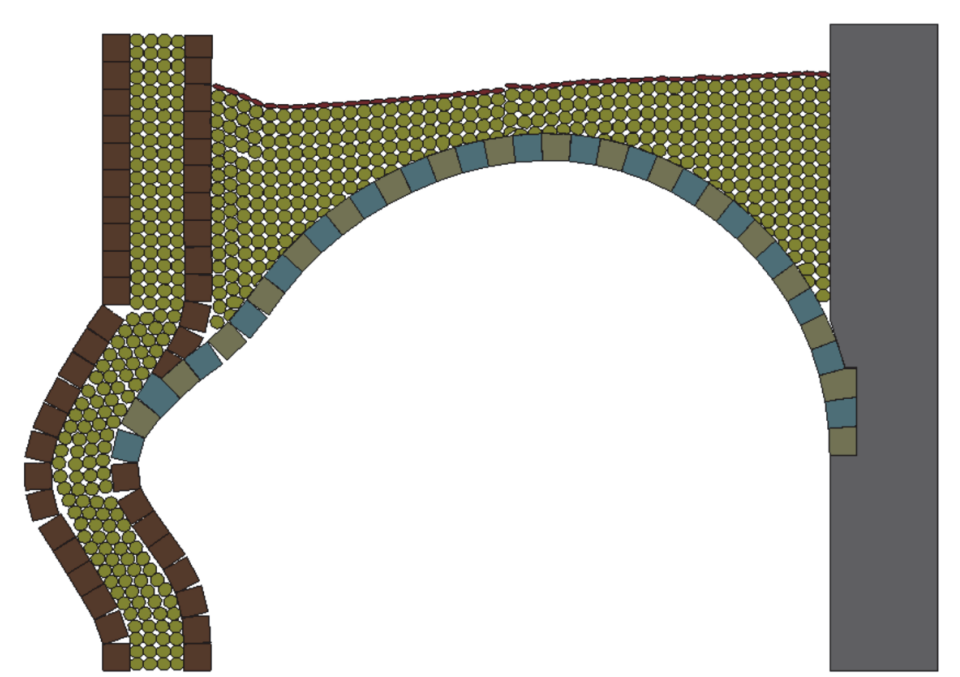

Figure 6: Deformed configuration after $0.9 \mathrm{sec}$ for scenario S2 $(\mathrm{L}=7.1 \mathrm{~m})$.

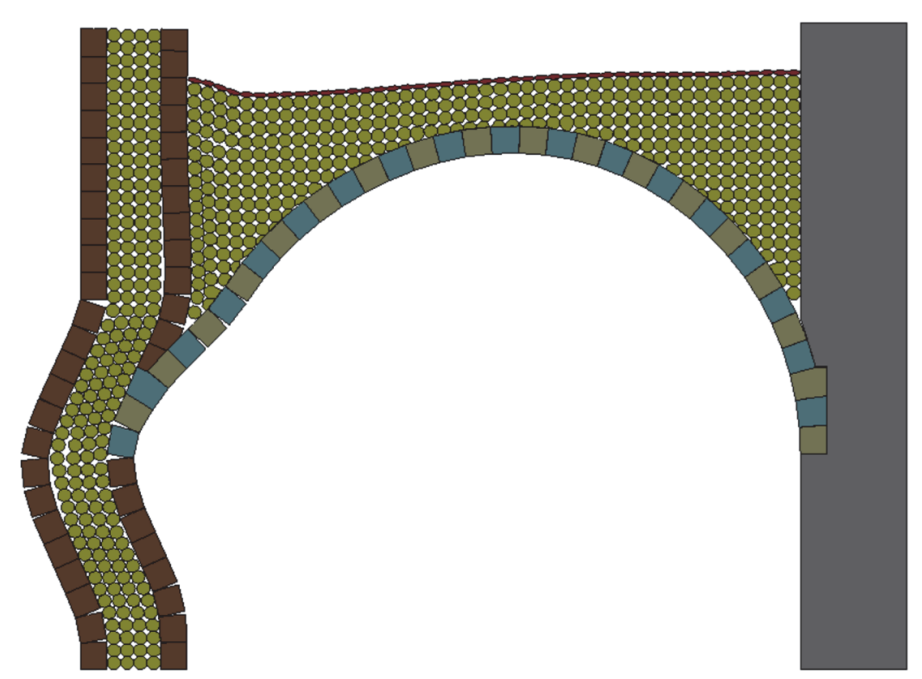

Figure 7: Deformed configuration after $0.9 \mathrm{sec}$ for scenario S3 $(\mathrm{L}=5 \mathrm{~m})$ 
Furthermore, the force time histories are reported at two different points (Fig. 8).

\section{Control point (collapsed wall)}

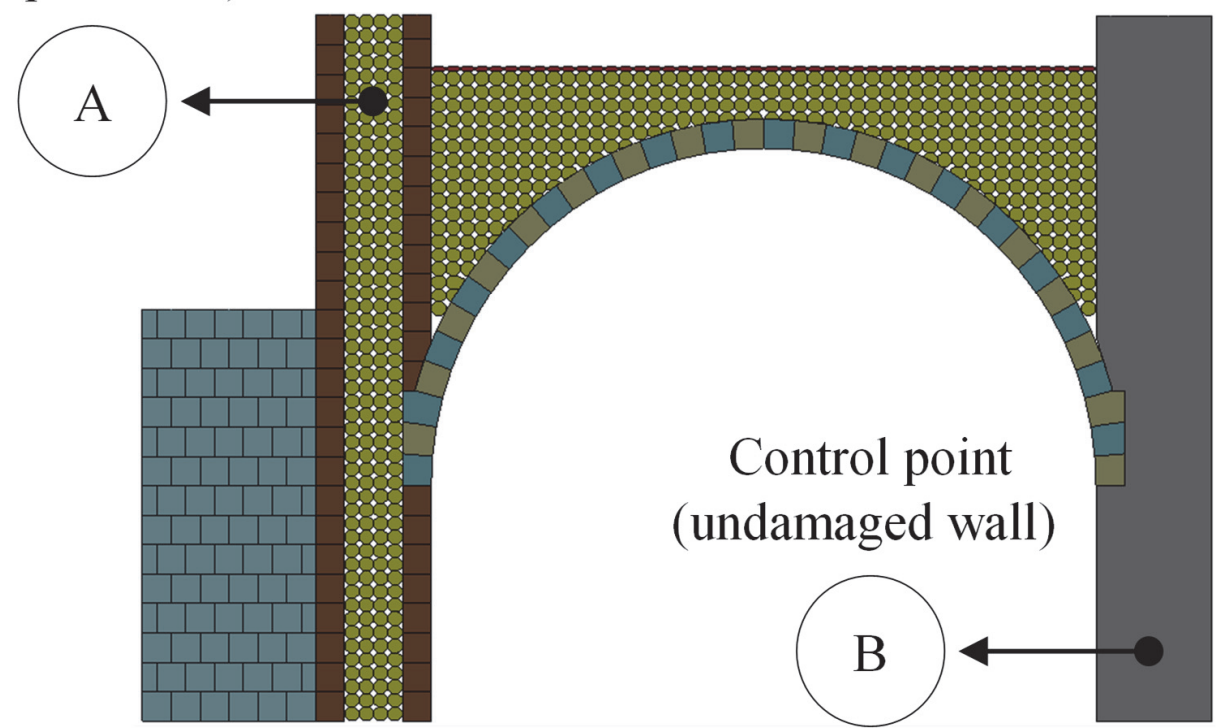

Figure 8: Control points for the force time-histories: A, in the collapsed wall, and, B, in the undamaged wall

Fig. 9 refers to the left wall, adjacent to the contrasting block that is demolished, and which is the one that collapsed. The graph shows the vertical stress (force) at one point in the wall (A in Fig. 8). Reference is made to the second scenario ( $\mathrm{L}$ equal to 7.1 meters). In the first 10 seconds the loading phase takes place. From 10 to 15 seconds the attenuation of the free oscillations is observed. In addition, some disturbance can also be observed due to the change of constrains. At 15 seconds, the contrasting block is demolished and the collapse initiates. At this point, the vertical force diminishes rapidly.

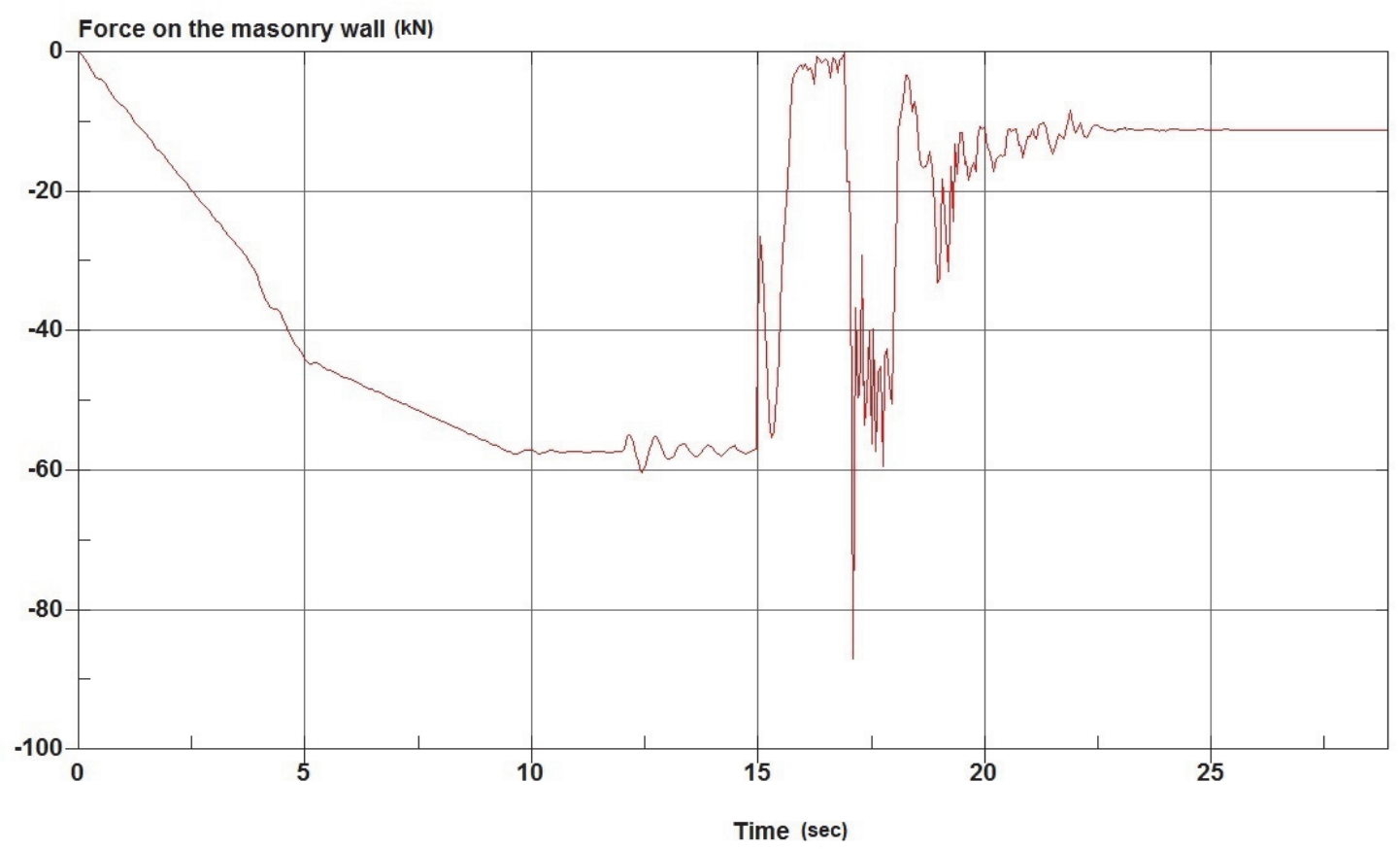

Figure 9: Force time history on the collapsed wall 
Fig. 10 reports the vertical force time history inside the other wall, the one that did not collapse. The situation is similar, with the gravity force rising, however after the elimination of the retaining block, the vertical force tends to a value equal to the self-weight of the column. This is something that could be expected since the problem is not symmetrical, in the sense that the right column does not collapse.

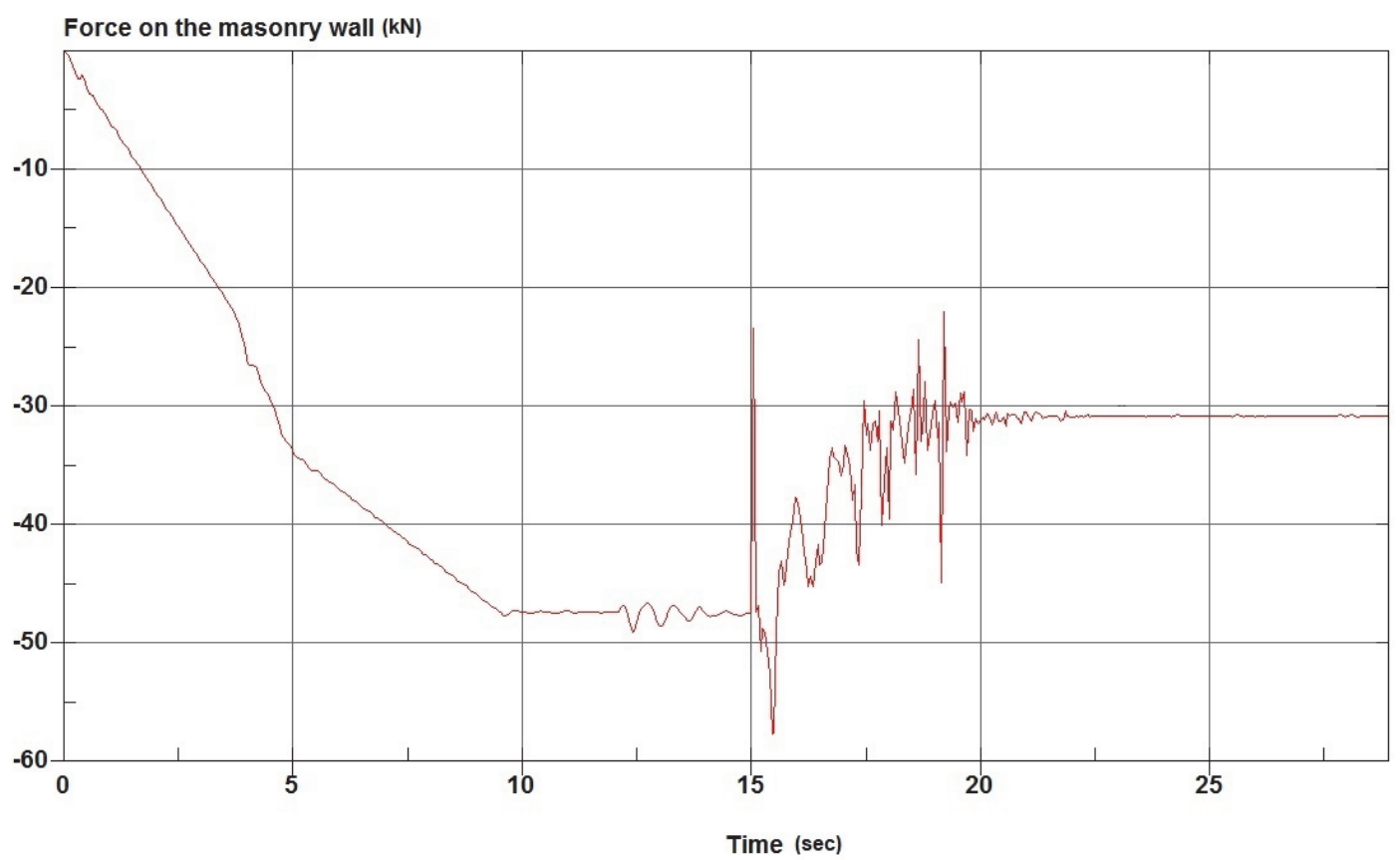

Figure 10: Force time history on the non-collapsed wall

\section{CONCLUSIONS}

he authors provided a simplified method for the assessment of the collapse of a masonry structure. In the performed analyses, the principal point was to capture the disintegration of the structural system "vault - external wall". Regarding this last, its components disintegrate in the well-cut piece of stones that form the curved part, the sustained part that is over the curved line of the vault and provide the horizontal level of the floor, and the external wall as composed by the two external layers made by ordered stones and the internal strengthless material.

In the experience of the authors, the ability (or the necessity) to simulate this disintegration is the focal point of the numerical analysis, while other detailed aspects, like the fine-tuning of material characteristics are secondary. It is obvious that this consideration is very critical toward modeling based on continuum theories.

The methodology proposed, can be an important aid also in the preliminary forensic investigation of masonry structure collapse.

\section{REFERENCES}

[1] Huerta Fernández, S. (2001). Mechanics of masonry vaults: The equilibrium approach. In: Historical Constructions. Possibilities of numerical and experimental techniques. Universidade do Minho, Guimaraes, Portugal, pp. 47-69.

[2] Creazza, G., Saetta, A., Matteazzi, R., Vitaliani, R. (2002). Analyses of masonry vaults: a macro approach based on three-dimensional damage model. J. Struct. Eng. 128(5), pp. 646-654.

[3] Block, P., Ciblac, T., Ochsendorf, J.A. (2006). Real-time limit analysis of vaulted masonry buildings. Comput. Struc. Vol. 84, No. 29-30, pp.1841-1852.

[4] Milani, G.; Lourenço, Paulo B.; Tralli, A. (2006). Homogenised limit analysis of masonry walls, Part I: failure surfaces. Comput. Struct. 84(3-4), pp. 166-180. 
[5] Milani, G.; Lourenço, Paulo B.; Tralli, A. (2006). Homogenised limit analysis of masonry walls, Part II: structural examples", Comput. Struct. 84(3-4), pp. 181-195.

[6] Caliò, I.; Cannizzaro, F.; Marletta, M. (2010). A Discrete Element for Modeling Masonry Vaults. Advanced Materials Research. 133-134, pp. 447-452.

[7] Tzamtzis, A.D., Asteris, P.G. (2003). Finite element analysis of masonry structures: part I- review of previous work. North American Masonry Conference, Clemson, South Carolina.

[8] Lourenço, P. (1996). Computational strategies for masonry structures. Civil Eng., Delft Univ. of Tech., PhD.

[9] Giresini, L., Sassu, M., Butenweg, C., Alecci, V., De Stefano, M. (2017). Vault macro-element with equivalent trusses in global seismic analyses, Earthquakes and Structures, 12(4), pp.409-423.

[10] Palmisano, F. (2014). Assessment of masonry arches and domes by simple models. International Journal of Structural Engineering, 5(1), pp. 63-75.

[11] Rovero, L., Alecci, V.,Mechelli, J., Tonietti, U., De Stefano, M. (2016). Masonry walls with irregular texture of L'Aquila (Italy) seismic area: validation of a method for the evaluation of masonry quality. Materials and Structures, 49, pp. 22972314.

[12] Borri, A., Corradi, M., Castori, G., De Maria, A. (2015). A method for the analysis and classification of historic masonry. Bull Earthq. 13(9), pp. 2647-2665.

[13] Maione, A., Argiento, L.U., Casapulla, C., Prota, A. (2018). Management of multisource information to identify the typology of the horizontal structures in ancient masonry buildings: the case study of the Museum of Capodimonte in Naples (Italy), Frattura ed Integrità Strutturale, 46, pp. 240-251.

[14] Pina-Henriques, J., Lourenço, P.B. (2004). Masonry Micro-Modelling adopting a Discontinuous Framework, in B.H.V. Topping, C.A. Mota Soares, (Editors). Proceedings of the Seventh International Conference on Computational Structures Technology, Civil-Comp Press, Stirlingshire, UK, Paper 195. DOI:10.4203/ccp.79.195.

[15] Palmisano, F. (2014). Assessment of masonry arches and domes by simple models. International Journal of Structural Engineering (IJSTRUCTE), 5(1).

[16] Kamal, O.A., Hamdy, G.A. and El-Salakawy, T.S. (2014). Nonlinear analysis of historic and contemporary vaulted masonry assemblages, HBRC Journal 10, pp. 235-246.

[17] Barbato, M., Palmeri, A. and Petrini, F. (2014). Special Issue on Performance-based engineering, Engineering Structures, 78, pp. 1-2.

[18] Eurocode 8. (2005). Eurocode 8: Design of Structures for Earthquake Resistance, Part 3: Assessment and Retrofitting of Buildings. EN 1998;3:2005. Brussels: CEN.

[19] Forlino, M., Arangio, S. (2015). Structural analysis for the forensic investigation of the demolition of a masonry structure. Ingegneria Forense, Crolli, Affidabilità Strutturale e Consolidamento. Proceedings of the IF CRASC '15 conference 14/16 May 2015, Rome, Nicola Augenti \& Franco Bontempi (eds), Dario Flaccovio Editore, pp. 467-477.

[20] Bakeer, T. \& Jäger, W., Schöps, P. (2009). Simulation of Masonry in ANSYS and LS-DYNA - The Features and Challenges. In: ANSYS Conference \& 27th CADFEM Users’ Meeting, CADFEM GmbH, Germany.

[21] Olmati P, Gkoumas K. (2015). Simplified FEM modelling for the collapse assessment of a masonry vault. Ingegneria Forense, Crolli, Affidabilità Strutturale e Consolidamento. Proceedings of the IF CRASC '15 conference - 14/16 May 2015, Rome, Nicola Augenti \& Franco Bontempi (eds), Dario Flaccovio Editore, 8.

[22] Palmisano, F., Perilli, P. (2017). Forensic Investigations of Collapses of Buildings in "Aggregate": Lesson Learnt from a Meaningful Case Study, Structural Engineering International 27(3), pp. 394-401. 